\title{
DEVELOPMENT OF A THIN GAUGE METALLIC SEAL FOR GAS TURBINE ENGINE APPLICATIONS TO $1700^{\circ} \mathrm{F}$
}

\author{
Raymond O. England \\ EG\&G Mechanical Components Research and Development Center
}

Cranston, Rhode Island

The goal of doubling thrust-to-weight ratio for gas turbine engines has placed significant demands on engine component materials. Operating temperatures for static seals in the transition duct and turbine sections, for instance, may well reach $2000^{\circ} \mathrm{F}$ within the next ten years. At these temperatures conventional age-hardenable superalloys loose their high strength via overaging and eventual dissolution of the $\gamma^{*}$ precipitate, and are well above thcir oxidation stability limit. Conventional solid-solution-strengthened alloys offer metallurgical stability, but suffer from rapid oxidation and little useful load bearing strength. Ceramic materials can theoretically be used at these temperatures, but manufacturing processes are in the developmental stages.

The development of a thin gauge metallic seal for operating temperatures up-to $1700^{\circ} \mathrm{F}$ is presented. The results of stress relaxation and oxidation screening tests for seven candidate alloys in strip form are discussed. Component tests using static loading in a seal chamber fixture correlate well with the stress relaxation and oxidation tests, and indicate that seals made from a new iron-based superalloy offer superior resistance to oxidation. metallurgical stability, and significant residual sealing force up to $672 \mathrm{~h}$ continuous exposure at $1700^{\circ} \mathrm{F}$. 